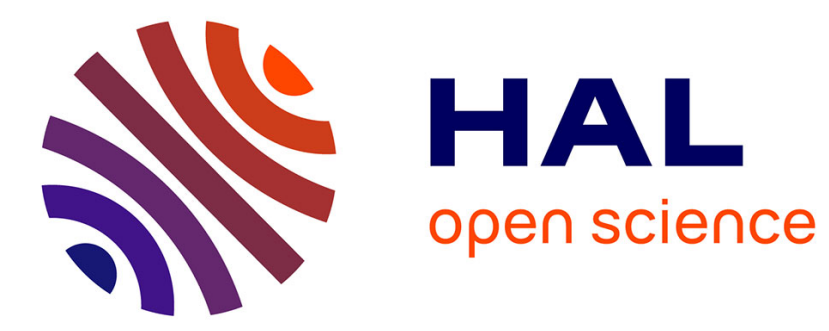

\title{
Posture Assessment and Subjective Scale Agreement in Picking Tasks with Low Masses
}

\author{
Olfa Haj Mahmoud, Charles Pontonnier, Georges Dumont, Stéphane Poli, \\ Franck Multon
}

\section{- To cite this version:}

Olfa Haj Mahmoud, Charles Pontonnier, Georges Dumont, Stéphane Poli, Franck Multon. Posture Assessment and Subjective Scale Agreement in Picking Tasks with Low Masses. AHFE - 11th Applied Human Factors and Ergonomics Conference, Jul 2020, San Diego, United States. hal-02495299

\section{HAL Id: hal-02495299 \\ https://hal.science/hal-02495299}

Submitted on 1 Mar 2020

HAL is a multi-disciplinary open access archive for the deposit and dissemination of scientific research documents, whether they are published or not. The documents may come from teaching and research institutions in France or abroad, or from public or private research centers.
L'archive ouverte pluridisciplinaire $\mathbf{H A L}$, est destinée au dépôt et à la diffusion de documents scientifiques de niveau recherche, publiés ou non, émanant des établissements d'enseignement et de recherche français ou étrangers, des laboratoires publics ou privés. 


\title{
Posture Assessment and Subjective Scale Agreement in Picking Tasks with Low Masses
}

\author{
Olfa Haj Mahmoud ${ }^{1,2}$, Charles Pontonnier ${ }^{2}$, Georges Dumont ${ }^{2}$, Stéphane Poli ${ }^{1}$, and \\ Franck Multon ${ }^{3}$ \\ ${ }^{1}$ FAURECIA Automotive Seating, Etampes, France \\ ${ }^{2}$ Univ Rennes, CNRS, Inria, IRISA-UMR6974, M2S, 35042 Rennes, France \\ ${ }^{3}$ Inria, Univ Rennes, CNRS, IRISA-UMR6974, M2S, 35042 Rennes, France \\ \{olfa.hajmahmoud, stephane.poli\}@faurecia.com, \{olfa.haj-mahmoud, charles.pontonnier, \\ Georges.Dumont, franck.multon \}@irisa.fr
}

\begin{abstract}
This study aims at analyzing the relationship between postural assessment and perceived discomfort for picking tasks with low mass $(1 \mathrm{~kg})$, involving a wide range of positions/postures. We analyzed the agreement of the different postural scores (mean value, integral value, root mean square value, weighted average time at each RULA level and the \% of time per RULA level) with the subjective assessments. The statistical analysis showed no correlation between subjective and postural scores. A few negative correlations were also noticed, especially for time spent at specific levels of postural discomfort compared to subjective feedback. The results showed that the subjective assessment was not correlated with the postural assessment in such low discriminant tasks. Although postural assessment enabled to discriminate the more difficult postures with regard to the experimental conditions, the subjects were unable to report coherent discomfort feedback.
\end{abstract}

Keywords: Ergonomics $\cdot$ RULA $\cdot$ Motion Capture $\cdot$ CP-50

\section{Introduction}

Assessing arduousness in work environments can be an effective mean to prevent the musculoskeletal disorders (MSD) that affect the different body parts, causing pain and discomfort, thus affecting, the daily work activities. Evaluating arduousness is a complex problem that entails several factors: biomechanical factors such as posture, repetition, force..., and psychosocial factors like stress, social status... [1]. Several tools have been developed in order to quantify ergonomic risks related to biomechanical factors. These methods can be classified into three groups according to the approach used in measurement [2]: (1) self-report, (2) observational [3, 4], and (3) direct measurement methods.

Self-report methods can be presented under different forms such as rating scales i.e. Borg scale [5] and CP-50 [6], checklists, questionnaires and interviews. The measurements using rating scales are based on the person's physical and mental sensitiveness; they vary depending on physical and environmental conditions. Observational methods 
are also used by ergonomists to evaluate different kinds of risks. NIOSH lifting equation can be used to assess risks mainly based on the load used in manual handling tasks [7]. Occupational Repetitive Actions (OCRA) [8] is mainly used to focus on frequency factors in repetitive tasks. The postural risk can be evaluated by using Rapid Upper Limb Assessment (RULA) method [9] or Rapid Entire Body Assessment (REBA) [10]. The posture score is divided into two groups: upper arms, lower arms and wrist for the first group and neck, trunk and legs for the second one. This score is adjusted with factors related to load handled and repetitive muscular activity to obtain the postural final scores, which varies from 1 for low risks to 7 for high postural risks in the case of RULA [9]. In all observational methods, the joint angles of different body segments and the load manipulated by the worker are scored using a worksheet corresponding to a collected key posture. The results validity for the observational methods depends on the collected input data [11], inter-rater reliability [12, 13]. To partly tackle this problem, observation could be replaced by direct measurements by using motion capture systems, such as optoelectronic systems or Microsoft Kinect [14, 15]. As arduousness at work is a multivariate phenomenon, assessing arduousness requires combining different methods. We could expect that combining various biomechanical, physiological and psychological factors would be correlated with the subjective feedback of the subject. But this correlation between subjective and objective measurements seems to be quite complex. Chihara et al. [16] reported little agreement between CP-50 and RULA for manual material handling tasks, when using 0 to $10 \mathrm{Kg}$ loads. In this paper, we propose to investigate this correlation for picking tasks with low mass, but with a high range of postures/positions, and continuous RULA measurement instead of static ones.

\section{Materials and Methods}

\subsection{Protocol}

We carried-out an experiment with 14 healthy subjects (five females and nine males); age $(27.07 \pm 7.6$ years $)$, stature $(172 \pm 11 \mathrm{~cm})$ and body mass $(65.64 \pm 11.24 \mathrm{Kg})$ respectively. The protocol was approved by a French national ethics committee (South West and Overseas 4 Persons Protection Committee) and registered under the reference $n^{\circ}$ 2019-A00218-49.

The experimental set-up was composed of a four-levels shelf of 40, 100, 170, 230 $\mathrm{cm}$ height and $30 \mathrm{~cm}$ left, middle and $30 \mathrm{~cm}$ right positions. A table was placed either to the right or left depending on the predominant subject hand. Twelve one-liter bottles, numbered from 1 to 12 were placed on the table in a random order. Before starting the experiment, each subject was asked to sign a consent form and was given a brief introduction on what the experiment was about in case he has questions or concerns.

At the beginning of each trial, the experimenter arranged the 12 bottles according to a random combination displayed in front of him. This random combination guaranteed the uniqueness of the order associated with each of the trials and prevented task-learning effects. Fig.1 represents a subject performing the experimentation. For each trial, the subject was facing the shelf. The bottles were placed on the table on the predominant subject side. The subject grabbed each bottle and placed it in the corresponding place. After placing a bottle, the subject had to evaluate the discomfort of the task according 
to the CP-50 scale. CP-50 defines five global categories of discomfort defined as follows: very slight discomfort, slight discomfort, discomfort, severe discomfort and very severe discomfort. After choosing a global category, the subject indicated the specific level of discomfort in the category on a 10-points scale. Paper labels were used in this experiment allowing the subject to note the difficulty for each task by placing the labels in front of the bottle. For each bottle, the subjects had to rate discomfort using these labels. The order was to compare the discomfort of picking and placing this bottle at the current placement, to the one in the middle level of the shelf. This latter placement was supposed to be the most comfortable configuration for all subjects, according to the French norm NF X35-109 [17]. More specifically, this norm assumes that the most comfortable position is between $75 \mathrm{~cm}$ and $110 \mathrm{~cm}$ for handling tasks. The subject returned to the table and took a new bottle for a new placement, and restarted the assessment process, for all the 12 bottles (a trial is defined as a picking and placing a set of 12 bottles). Once all bottles were placed on the shelf, the trial ended followed by a rest period before starting a new trial.

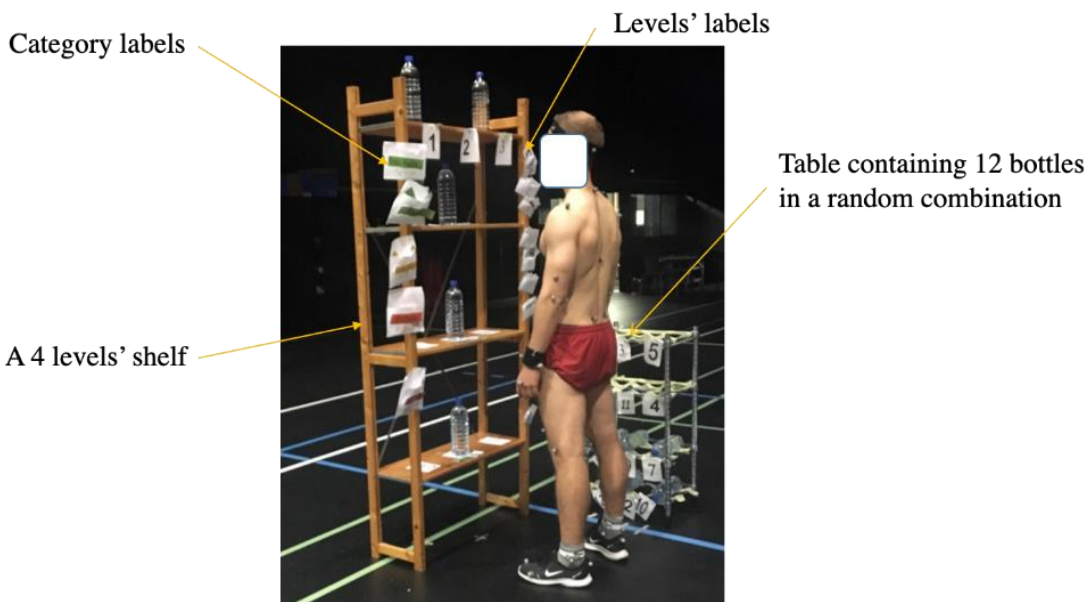

Fig.1. A subject equipped with the 43 reflective markers following the ISB recommendations [18] facing the shelf, the table on his right and the bottles in a random combination.

An optoelectronic motion capture system Qualisys (composed of 23 12-Mpixels cameras, $200 \mathrm{~Hz}$ sampling frequency) was used to track 43 reflective markers placed on standardized anatomical landmarks, following the ISB (International society of Biomechanics) recommendations [18].

\subsection{Data Processing}

Based on the 3D position of the anatomical landmarks captures with the Qualisys system, joint angles were computed following ISB recommendations [18]. RULA scores were then computed using these joint angles. The RULA method involves adjustments for shoulder abduction $\backslash$ adduction movements, lateral flexion of the trunk. The threshold 
was set to $20^{\circ}$ for the trunk and the wrist as suggested in [15], and $45^{\circ}$ for the abduction $\backslash$ adduction of the shoulder. To compare the RULA score with the CP-50 score, both scores were normalized. The RULA score was normalized by the maximum of each score for all the bottles. Similarly, the CP-50 was normalized by the maximum of all placements of a trial. The RULA score was computed continuously all along the task at $200 \mathrm{~Hz}$, whereas CP50 was collected as a unique score for each bottle placement. To obtain a unique postural score derived from RULA for each bottle, we tested different assumptions: the mean value of the continuous RULA score (1), the integral value (2), the Root Mean Square value (3), the weighted average time at each RULA level (4) and the $\%$ of time per RULA level (5).

$$
\begin{gathered}
\text { Mean }=\frac{\sum_{\mathrm{i}=1}^{\mathrm{N}} \operatorname{RULA}(i)}{N} \\
\text { Integral }=\int_{\mathrm{t}=1}^{\mathrm{N}} \operatorname{RULA}(\mathrm{t}) \mathrm{dt} \\
R M S=\sqrt{\frac{\sum_{i=1}^{N} R U L A^{2}(\mathrm{i})}{N}} \\
\text { Weighted average time at each RULA level }=\frac{\sum_{\mathrm{i}=1}^{7} \alpha_{\mathrm{i}} * \operatorname{count}(R U L A=i)}{\sum_{\mathrm{i}=1}^{7} \alpha_{\mathrm{i}}} \\
\% \text { of time per RULA level: } \forall i=1: 7, \text { level }_{i}=100 \frac{\operatorname{count}(R U L A=i)}{N}
\end{gathered}
$$

With

$\mathrm{N}$ : total number of frames.

RULA (i): the value of RULA at frame $i$.

Count (RULA=i): the number of frames where RULA value equals $i$.

$\alpha_{\mathrm{i}}$ : weights applied to Count (RULA $=\mathrm{i}$ ). In this paper we have chosen $\forall i, \alpha_{\mathrm{i}}=\mathrm{i}$ to give more weight for important RULA scores.

RULA: The time spent in each score level of RULA.

To explore the correlation between scores derived from RULA and subjective ratings of the discomfort of the task, a principal component analysis (PCA) was performed using a pxm matrix where $p$ is the total number of subjects and $m=6$ ( 5 scores derived from RULA and one CP-50 score). The highest PCA coefficients were selected (leading to explain at least $80 \%$ of the variance). To evaluate the consistency of the subjects' ratings for the different trials using the CP-50, an intra-class correlation coefficient (ICC) was computed. The difference between subjects' responses were also compared. This method allowed to explore how consistent were the ratings with regard to the experimental conditions. 


\section{Results and Discussion}

Table 1: PCA coefficients for different assumptions and the (\%) of total variance for the first three components.

\begin{tabular}{|l|l|l|l|l|l|l|l|l|l|}
\hline \multicolumn{2}{|c|}{} & \multicolumn{7}{|c|}{ Coefficient relating to the different assumptions } \\
\hline \multicolumn{1}{|c|}{$\begin{array}{c}\text { Total Va- } \\
\text { riance (\%) }\end{array}$} & Mean & $\begin{array}{c}\text { Inte- } \\
\text { gral }\end{array}$ & RMS & $\begin{array}{c}\text { Weighted } \\
\text { average } \\
\text { time }\end{array}$ & CP-50 & $\begin{array}{c}\text { \%time- } \\
\text { RULA } \\
=4\end{array}$ & $\begin{array}{c}\text { \%time- } \\
\text { RULA } \\
=\mathbf{6}\end{array}$ & $\begin{array}{c}\text { \%time- } \\
\text { RULA=7 }\end{array}$ \\
\hline $\begin{array}{l}\text { First } \\
\text { Com- } \\
\text { po- } \\
\text { nent }\end{array}$ & 29.57 & 0.03 & 0.03 & 0.03 & 0.003 & $\mathbf{0 . 9 9}$ & -0.007 & 0.03 & 0.01 \\
\hline $\begin{array}{l}\text { Se- } \\
\text { cond } \\
\text { Com- } \\
\text { po- } \\
\text { nent }\end{array}$ & 25.67 & 0.25 & 0.25 & 0.26 & 0.10 & -0.05 & -0.29 & 0.73 & 0.05 \\
\hline $\begin{array}{l}\text { Third } \\
\text { Com- } \\
\text { po- } \\
\text { nent }\end{array}$ & 23.81 & 0.11 & 0.11 & 0.08 & 0.03 & 0.06 & 0.82 & -0.04 & -0.03 \\
\hline
\end{tabular}

Table 1 shows the results of the three first components of the PCA that described $79.05 \%$ of the total variance. The first component with $29.57 \%$ of the total variance was mainly based on CP-50 (99\%). All the postural scores derived from RULA appear in the second and third components with $25 \%$ for the mean RULA score value, $26 \%$ for the root mean square RULA score value. The percentage of time spent at specific RULA levels (\%time RULA=1, 2, 3 and 5) were not significant in these three first components and therefore not reported here. We noticed a few negative correlations especially with the \%time spent at RULA score equal to 4. The PCA results reveal that no correlation exists between the CP-50 and the postural scores derived from RULA. The ICC for all subjects and all trials was equal to 0.326 , demonstrating a poor consistency of the intra and inter-subjects' ratings (CP-50 answers) with regard to the experimental conditions (bottle location on the shelf). We found poor correlation between $\mathrm{CP}-50$ and postural scores, in agreement with the PCA analysis. Hence, although RULA scores enabled us to distinguish differences between the postures, our results show that discomfort reported by the subjects where inconsistent. Subject did not feel enough changes in the experimental conditions to clearly identify higher levels of discomfort for extreme postures (highest and lowest levels of the shelf for example). The CP-50 scale may also be too complex for such a task and may had resulted in a larger dispersion of the results. Concurrently, the scores derived from RULA logically reached higher levels for - assumed- more extreme postures. In the literature [16] showed a small agreement between CP-50 and RULA scores for handling task with 0 to $10 \mathrm{Kg}$ load. Similarly, [19] showed an agreement between RPE and physiological parameters 
for handling tasks with $23 \mathrm{Kg}$ load. Ours results seems to indicate that this agreement vanishes for the lowest load levels $(1 \mathrm{~kg})$. This result is in accordance with previous work [3] demonstrating that the heavier the weight is, the higher the correlation between postural and subjective assessment is.

\section{Conclusion}

In this study, the agreement between postural discomfort scores derived from RULA and self-report discomfort scores was investigated to explain the arduousness of the task. The major findings are:

1. The ICC of the subjects CP-50 ratings was low, indicating a poor consistency of the intra and inter subject answers with regard to the experimental conditions (here the postural changes related to the bottle placement).

2. The PCA analysis of the scores indicated that the postural assessment and the subject's answers were not correlated, in agreement with previous works.

Future works will involve a simpler rating scale to simplify the assessment for the subjects. The mass will also be increased to check the agreement found in the literature for such a task. The posture holding time will also be extensively investigated, since it is supposed to be a discriminant parameter to evaluate discomfort over time. Another interesting perspective would consist in investigating the subject fatigue with regard to repetitive tasks performed with low loads.

\section{References}

1. Robert S Bridger. Introduction to ergonomics, volume 53. Taylor \& Francis e-Library, 2003.

2. Spielholz, P., Silverstein, B., Morgan, M., Checkoway, H., \& Kaufman, J. (2001). Comparison of self-report, video observation and direct measurement methods for upper extremity musculoskeletal disorder physical risk factors. Ergonomics, 44(6), 588-613.

3. Stephen Bao, Peregrin Spielholz, Ninica Howard, and Barbara Silverstein. Force measurement in field ergonomics research and application. International Journal of Industrial Ergonomics, 39(2):333-340, 2009.

4. Geoffrey David, Valerie Woods, Guangyan Li, and Peter Buckle. The development of the Quick Exposure Check (QEC) for assessing exposure to risk factors for work-related musculoskeletal disorders. Applied Ergonomics, 39(1):57-69, 2008.

5. Gunnar Borg. Borg's perceived exertion and pain scales. Human Kinetics, (July 1998):104 vii, 1998.

6. Wenqi Shen and Kenneth C. Parsons. Validity and reliability of rating scales for seated pressure discomfort. International Journal of Industrial Ergonomics, 20(6):441-461, 1997.

7. Waters Tomas R, Putz-Anderson Vern, and Garg Arun. Application Manual for the Revised NIOSH Lifting Equation. PB94-176930. 1994.

8. Enrico Occhipinti. OCRA: A concise index for the assessment of exposure to repetitive movements of the upper limbs. Ergonomics, 41(9):1290-1311, 1998.

9. McAtamney and Nigel Corlett. RULA: A survey method for the investigation of work-related upper limb disorders. Applied Ergonomics, 24(2):91-99, 1993. 
10. Lynn McAtamney and Sue Hignett. Rapid Entire Body Assessment. Handbook of Human Factors and Ergonomics Methods, 31:8-1-8-11, 2004.

11. Mircea Fagarasanu and Shrawan Kumar. Measurement instruments and data collection: A consideration of constructs and biases in ergonomics research. International Journal of Industrial Ergonomics, 30(6):355-369, 2002.

12. Sara Dockrell, Eleanor O'Grady, Kathleen Bennett, Clare Mullarkey, Rachel Mc Connell, Rachel Ruddy, Seamus Twomey, and Colleen Flannery. An investigation of the reliability of Rapid Upper Limb Assessment (RULA) as a method of assessment of children's computing posture. Applied Ergonomics, 43(3):632-636, 2012.

13. Michelle Robertson, Benjamin C. Amick, Kelly DeRango, Ted Rooney, Lianna Bazzani, Ron Harrist, and Anne Moore. The effects of an office ergonomics training and chair intervention on worker knowledge, behavior and musculoskeletal risk. Applied Ergonomics, 40(1):124-135, 2009.

14. Vito Modesto Manghisi, Antonio Emmanuele Uva, Michele Fiorentino, Vitoantonio Bevilacqua, Gianpaolo Francesco Trotta, and Giuseppe Monno. Real time RULA assessment using Kinect v2 sensor. Applied Ergonomics, 65:481-491, 2017.

15. Pierre Plantard, Hubert P.H. Shum, Anne Sophie Le Pierres, and Franck Multon. Validation of an ergonomic assessment method using Kinect data in real workplace conditions. Applied Ergonomics, 65:562-569, 2017.

16. Takanori Chihara, Sanako Hoshi, and Akihiko SEO. 1B2-2 Fundamental Study on Formulation of Total Perceived Discomfort for the Entire Body in the Sagittal Plane based on Joint Moment. The Japanese Journal of Ergonomics, 5 Supplement S140-S141, 2014.

17. Ge Wu, Frans C.T. Van Der Helm, H. E.J. Veeger, Mohsen Makhsous, Peter Van Roy, Carolyn Anglin, Jochem Nagels, Andrew R. Karduna, Kevin McQuade, Xuguang Wang, Frederick W. Werner, and Bryan Buchholz. ISB recommendation on definitions of joint coordinate systems of various joints for the reporting of human joint motion - Part II: Shoulder, elbow, wrist and hand. Journal of Biomechanics, 38(5):981-992, 2005.

18. Kai Way Li, Rui feng Yu, Yang Gao, Rammohan V. Maikala, and Hwa Hwa Tsai. Physiological and perceptual responses in male Chinese workers performing combined manual materials handling tasks. International Journal of Industrial Ergonomics, 39(2):422-427, 2009.

19. Norme-NF-X35-109. Manutention manuelle de charge pour soulever, déplacer et pousser/tirer. Paris, AFNOR, page-17. 